\title{
The Type IV-Specific Phosphodiesterase Inhibitor Rolipram and Its Effect on Hippocampal Long-Term Potentiation and Synaptic Tagging
}

\author{
Sheeja Navakkode, Sreedharan Sajikumar, and Julietta Uta Frey \\ Leibniz Institute for Neurobiology, Department of Neurophysiology, D-39118 Magdeburg, Germany
}

We investigated the effects of rolipram, a selective cAMP phosphodiesterase (PDE) inhibitor, on late plastic events during functional CA1 plasticity in vitro in rat hippocampal slices. We present data showing that an early form of long-term potentiation (LTP) (early-LTP) that normally decays within 2-3 hr can be converted to a lasting LTP (late-LTP) if rolipram is applied during tetanization. This rolipramreinforced LTP (RLTP) was NMDA receptor and protein synthesis dependent. cAMP formation in region CA1 during late-LTP requires dopaminergic receptor activity (Frey et al., 1989, 1990). Thus, we studied whether RLTP was influenced by inhibitors of the $D_{1} / D_{5}$ receptor. Application of the specific $\mathrm{D}_{1} / \mathrm{D}_{5}$ antagonist $\mathrm{SCH} 23390(0.1 \mu \mathrm{M})$ did not prevent RLTP, suggesting that the phosphodiesterase inhibitor acts downstream of the $\mathrm{D}_{1} / \mathrm{D}_{5}$ receptors. We also studied whether rolipram can interact with processes of synaptic tagging, because RLTP was also dependent on protein synthesis, similar to late-LTP. Inhibition of PDE and subsequent induction of RLTP in one synaptic population were able to transform early-LTP into late-LTP in a second, independent synaptic population of the same neurons. This supports our hypothesis that cAMP-dependent processes are directly involved in the synthesis of plasticity-related proteins.

Key words: rolipram-reinforced LTP (RLTP); synaptic tagging; protein synthesis; long-term potentiation; functional plasticity; phosphodiesterases

\section{Introduction}

Hippocampal long-term potentiation (LTP) is considered a model for functional plasticity and the processes of learning and memory (Bear and Malenka, 1994; Linden, 1996; Sajikumar and Frey, 2003). Interestingly, LTP and memory formation are characterized by similar temporal phases. An early form of LTP (early-LTP), lasting $<4 \mathrm{hr}$, can be dissociated from lasting LTP (late-LTP) by blockers of protein synthesis (Krug et al., 1984; Frey et al., 1988; Otani et al., 1989). Additionally, late-LTP depends on the activation of a cAMP-dependent protein kinase (PKA) (Frey et al., 1993; Matthies and Reymann, 1993; Brandon et al., 1995; Nguyen and Kandel, 1996; Kameyama et al., 1998) via activation of $\mathrm{D}_{1} / \mathrm{D}_{5}$ receptors and a subsequent increase of cAMP in area CA1 in tissues from adult animals (Sajikumar and Frey, 2004). cAMP is a substrate of cAMP phosphodiesterases (PDEs), which constitute a large divergent family with $>50 \mathrm{mRNA}$-splicing isoforms (Rybalkin and Beavo, 1996; Loughney et al., 1999). Well characterized mutations that affect rolipram binding are primarily located in the binding pocket and are predicted to be in contact with cAMP substrate (Atienza et al., 1999). Therefore, PDE inhibitors can increase signaling through the cAMP system by inhibiting cAMP breakdown and thus activating PKA (Stone and

Received May 10, 2004; revised July 8, 2004; accepted July 13, 2004.

This work was supported by the Volkswagenstiftung Grant AZ I/77922 (J.U.F.).

Correspondence should be addressed to Julietta U. Frey, Leibniz Institute for Neurobiology, Department of Neurophysiology, Brenneckestrasse 6, D-39118 Magdeburg, Germany. E-mail: frey@ifn-magdeburg.de.

DOI:10.1523/JNEUROSCI.1796-04.2004

Copyright $\odot 2004$ Society for Neuroscience $\quad$ 0270-6474/04/247740-05\$15.00/0
John, 1990; DeLapp and Eckols, 1992). Rolipram is a PDE inhibitor that is selective for the $\mathrm{Ca}^{2+}$ /calmodulin-independent and cAMP-specific isozyme of PDE4 (Beavo, 1988). It has been found that rolipram increases cAMP levels in vitro (Donaldson et al., 1988) and in vivo (Schneider, 1984). Administration of cAMP analogs can induce late-LTP (Frey et al., 1993). In contrast to the artificial raise of cAMP by the analogs used in the latter study, PDE inhibitors maintain the basal cAMP concentration within a physiological range by inhibiting their metabolism. Thus, investigation of PDE inhibition by rolipram may reveal better, more physiological insights into mechanisms of functional late plasticity.

Imanishi et al. (1997) found an ameliorating effect of rolipram on learning and memory impairment in rodents. Rolipram reversed the impairment of either working or reference memory induced by the muscarinic receptor antagonist scopolamine (Egawa et al., 1997; Imanishi et al., 1997; Zhang and O'Donnell, 2000). Nonspecific PDE inhibitors, such as caffeine, improved behavioral performance under distinct conditions (Nicholson, 1990).

In mouse hippocampal CA1, rolipram reinforced a transient into a lasting potentiation (Barad et al., 1998). We replicated these results in rat hippocampal slices in vitro. Additionally, we were interested in investigating putative implications of PDE inhibition on processes of "synaptic tagging." Synaptic tagging describes a general mechanism how input specificity is achieved during a protein synthesis-dependent stage of LTP (Frey and Morris, 1997). Additionally, heterosynaptic activation of the syn- 
thesis of plasticity-related proteins (PRPs) can also influence weaker forms of plastic events induced in other independent, synaptic inputs of the same neurons if coactivation of these inputs occurred within a distinct time window ("lateassociativity") (Frey and Morris, 1997, 1998a,b). We now study whether rolipram-reinforced LTP (RLTP) in one input is able to influence early-LTP in a second input.

\section{Materials and Methods}

Seventy-six transversal hippocampal slices $(400 \mu \mathrm{m})$ were prepared from 767-week-old male Wistar rats as described previously (Frey and Morris, 1997, 1998b; Sajikumar and Frey, 2003). Slices were incubated within an interface chamber at a temperature of $32^{\circ} \mathrm{C}$ [a modified Krebs'-Ringer's solution containing (in mM): $124 \mathrm{NaCl}, 4.9 \mathrm{KCl}, 1.2 \mathrm{KH}_{2} \mathrm{PO}_{4}, 2.0 \mathrm{MgSO}_{4}$, $2.0 \mathrm{CaCl}_{2}, 24.6 \mathrm{NaHCO}_{3}$, and 10 [SCAP] D-glucose was used as an artificial corticospinal fluid (ACSF); carbogen consumption, $32 \mathrm{l} / \mathrm{hr}$ ]. In all of the experiments, two monopolar lacquer-coated, stainless-steel electrodes were positioned within the stratum radiatum of the CA1 region for stimulation of two separate independent synaptic inputs, S1 and S2. For recording of the field EPSP and the population spike, two electrodes were placed in the CA1 dendritic and cell body layer of a single neuronal population, respectively (Frey and Morris, 1997, 1998b). Slices were preincubated for at least $4 \mathrm{hr}$ before recording the baseline, a period that is critical for a stable long-term recording (Sajikumar and Frey, 2004).

After the preincubation period, the test stimulation strength was determined to elicit a population spike of $25 \%$ of its maximal amplitude. In cases in which a low-frequency control input was monitored, a stimulation intensity that elicited $40 \%$ of the maximal population spike amplitude was determined. The population spike amplitude and the slope of the field EPSP were monitored on-line. Baseline was recorded for a minimum period of $1 \mathrm{hr}$ before LTP induction (four $0.2 \mathrm{~Hz}$ biphasic constant-current pulses every $15 \mathrm{~min}$; impulse width, $0.1 \mathrm{msec}$ per halfwave; averaged on-line). In experiments with induction of early-LTP, a single tetanus with 21 biphasic constant-current pulses was used ("weak" tetanus, $100 \mathrm{~Hz}$; impulse width duration, $0.2 \mathrm{msec}$ per polarity; stimulus intensity for tetanization, population spike threshold). Four $0.2 \mathrm{~Hz}$ biphasic, constant-current pulses $(0.1 \mathrm{msec}$ per polarity) were used for testing $1,3,5,11,15,21,25$, and 30 min posttetanus, and then every 15 min.

Rolipram (Tocris Cookson, Bristol, UK), a type-IV PDE inhibitor, was used at a concentration of $0.1 \mu \mathrm{M}$ dissolved in ACSF and $0.1 \%$ dimethyl sulfoxide $(0.1 \%$ DMSO had no effect on control recordings; data not shown). D-2-Amino-5-phosphonopentanoic acid (AP-5) (Sigma, St. Louis, MO) was used at a concentration of $50 \mu \mathrm{M}$ (dissolved in ACSF) to block the NMDA receptor. Anisomycin (Sigma), a reversible protein synthesis inhibitor, was used at a concentration of $25 \mu \mathrm{M}$ (a concentration that blocked at least $85 \%$ of $\left[{ }^{3} \mathrm{H}\right]$ leucine incorporation into hippocampal slices) (Frey et al., 1991). Emetine (Tocris Cookson) was used at a concentration of $20 \mu \mathrm{M}$ (dissolved in ACSF and 0.1\% DMSO). The selective dopaminergic $\mathrm{D}_{1} / \mathrm{D}_{5}$ receptor $\mathrm{SCH} 23390$ was used at a concentration of $0.1 \mu \mathrm{M}$ (dissolved in ACSF; Tocris Cookson).

The average values of the population spike (in millivolts) and slope function of the field EPSP (in millivolts/millisecond) per time point were subjected to statistical analysis (Wilcoxon signed rank test when compared within one group or the Mann-Whitney $U$ test when data were compared between groups; $p<0.05$ considered statistically significant difference).

\section{Results}

The time course of the population spike resembled the one of the field EPSP. Thus, only the latter is described in detail and presented in the figures.

\section{Rolipram-induced reinforcement of early-LTP}

Induction of early-LTP in synaptic input S1 (Fig. 1b, closed circles) resulted in a transient statistically significant form of LTP with a duration of $2-3 \mathrm{hr}$ before returning to baseline values at which the potentials remained stable for the time of recording. A control input, S2, without application of high-frequency stimulation, remained stable at baseline level for the entire experimental session (Fig. 1b, open circles). Application of rolipram from 30 min before until 30 min after the induction of early-LTP in input S1 (filled circles) converted the transient early form of LTP into a statistically significant late form with a duration of at least $6 \mathrm{hr}$ (RLTP), the latest time point we recorded (Fig. $1 c$, filled circles). Control responses obtained from S2 (Fig. 1c, open circles) remained stable at baseline levels. Analyses of the input-output relationship before the application of rolipram and tetanization and $6 \mathrm{hr}$ after LTP induction revealed no differences when compared with rolipram-untreated slices. A comparable EPSP spike shift was seen in the tetanized input. The control input remained stable over the investigated $7 \mathrm{hr}$. We also did not note any effects of rolipram on LTP induction by analyzing the tetanization trains under the influence of the drug at the used concentration (data not shown). Next, we investigated whether the PDE inhibitor had to be present during the induction of early-LTP to be effective in generating RLTP or whether it would have been sufficient to apply rolipram after the induction of early-LTP. In the latter case, it could act via late-associative properties on the earlier tetanization of input $\mathrm{S} 1$ in a nonspecific way. Figure $1 d$ represents the time course of the field EPSP in which rolipram was applied shortly after the induction of early-LTP (15 min after tetanization in S1). In this case, rolipram was ineffective in affecting early-LTP (Fig. 1d, filled circles). Next, we examined whether NMDA receptor activation was required for RLTP. As shown in Figure 1e, coapplication of $50 \mu \mathrm{M}$ AP-5 prevented the induction of earlyLTP and RLTP. In this series, after recording a baseline for 50 min, AP-5 was applied for 10 min before being coapplied with rolipram for another hour. The following series of experiments studied the possible requirement of macromolecular synthesis for RLTP. The reversible protein synthesis inhibitor anisomycin was applied 10 min before coapplication with rolipram for an additional hour. Figure $1 f$, filled circles, shows that anisomycin did not prevent early-LTP but RLTP. Thus, the reinforcement of early-LTP by rolipram seems to be protein synthesis dependent. In all of the series of experiments, the control input S2 (open circles) was not influenced by the drugs or tetanization.

\section{Rolipram and processes of synaptic tagging}

RLTP seems to mimic protein synthesis-dependent late-LTP. Thus, the question arose whether processes of synaptic tagging can be detected, because only those inputs in which early-LTP was induced together with the application of rolipram showed RLTP (Fig. 1c). Thus, a first set of controls studied the possible interference of the subsequent induction of early-LTP in two separate synaptic inputs, S1 and S2. As shown in Figure $2 a$, earlyLTP of the two inputs was not influenced if the time interval between subsequent tetanization was $40 \mathrm{~min}$. However, when early-LTP was induced in S1 followed by the application of rolipram 15 min after tetanization of S1 (i.e., at a time point at which rolipram was ineffective in affecting the potentiation in that input) (Fig. $1 d$ ) and a subsequent induction of early-LTP in S2 was induced $40 \mathrm{~min}$ after tetanization of $\mathrm{S} 1$ but now under the influence of rolipram, both inputs, S1 and S2, paradoxically expressed late-LTP (Fig. 2b). We then investigated whether these rolipraminduced, associative prolongations of early-LTP require the synthesis of macromolecules. In the series shown in Figure $2 c$, we repeated the experiment represented in Figure $2 b$ with one exception. Here, anisomycin (5 min after tetanization of S1) was applied shortly before rolipram ( $15 \mathrm{~min}$ after tetanization). We also 
tested a second, structurally different inhibitor of protein synthesis to rule out any nonspecific effects of ansomycin (Fig. $2 c$, inset). Interestingly, in these cases, under protein synthesis inhibition the associative reinforcement of early-LTP in S1 and S2 was prevented. These data support the involvement of phosphodiesterases in processes of synaptic tagging.

We showed recently that protein synthesis-dependent processes of synaptic tagging in area CA1 specifically require the heterosynaptic activation of $D_{1} / D_{5}$ receptors during induction (Sajikumar and Frey, 2004). Thus, we were interested in whether the action of rolipram still requires $\mathrm{D}_{1} / \mathrm{D}_{5}$ receptor activation or whether $\mathrm{PDE}$ processes act downstream of $D_{1} / D_{5}$ receptors. Therefore, we now applied the selective $\mathrm{D}_{1} / \mathrm{D}_{5}$ receptor antagonist $\mathrm{SCH} 23390$ shortly before the application of rolipram (Fig. 2d) in the same manner as in the set with anisomycin (Fig. 2c). As shown in Figure $2 d$, synaptic tagging and the expression of RLTP in the two inputs S1 and S2 were not negatively influenced by the blockers of the dopaminergic receptors, supporting an action of the PDE downstream of the $\mathrm{D}_{1} / \mathrm{D}_{5}$ receptors. Interestingly, a tendency of enhanced potentiation was detected under these circumstances.

\section{Discussion}

The type IV-specific PDE inhibitor rolipram can prolong an early form of LTP, which normally decays within $2-3 \mathrm{hr}$, to a long-lasting form of LTP with a duration of at least $6 \mathrm{hr}$, the latest time point we investigated (Fig. 1b,c). The results obtained in hippocampal slices from rats confirm the findings in mice recently published by Barad et al. (1998). In addition to these data, we now describe that this reinforcement of early-LTP by rolipram is dependent on the activation of the NMDA receptor and on protein synthesis (Fig. $1 e, f)$. We showed recently that a type-IV PDE, PDE4B3, is specifically regulated in its expression and function during different phases of LTP (Ahmed and Frey, 2003; Ahmed et al., 2004). Furthermore, the induction of late-LTP requires the activation of PKA through cAMP-dependent processes (Frey et al., 1993). The substrate of the type-IV PDE is cAMP. Thus, rolipram, as a PDE inhibitor, may enhance the translational machinery by increasing cAMP levels and PKA activity. In addition, PDE-related processes that could counteract with potentiation-related intracellular processes would be depressed. Thus, early-LTP, a normally transient form of LTP that is characterized by the setting of protein synthesis-independent tags (Frey and Morris, 1997, 1998a), can be transformed into a protein synthesis-dependent late-LTP.

The notion that PDE4B3 is specifically regulated during a dif-
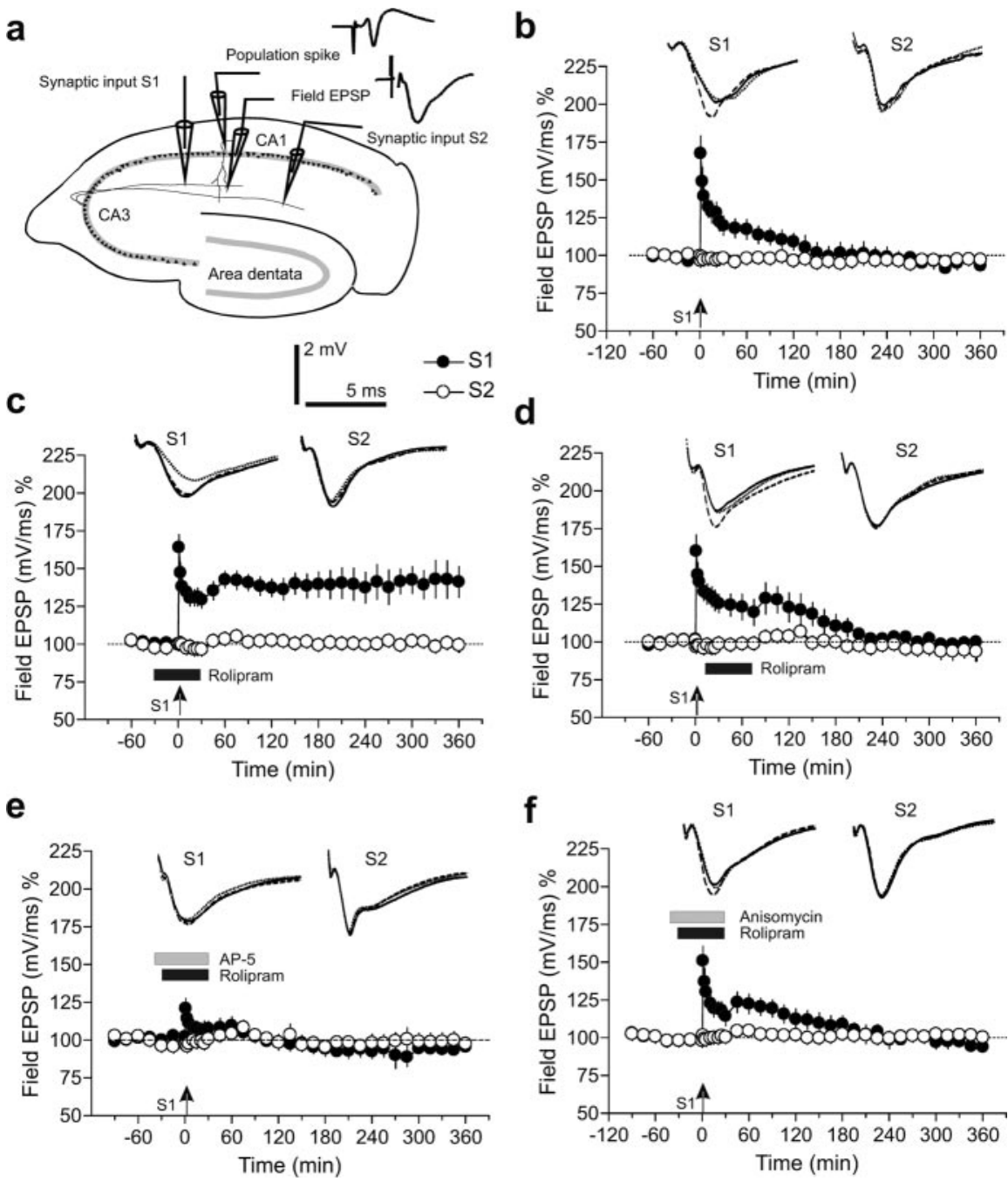

Figure 1. Properties of rolipram-reinforced early-LTP. $a$, Transversal hippocampal slice showing the positioning of the electrodes. The two independent inputs to the same neuronal population, S1 and S2, and the recording sites for the population spike amplitude and the field EPSP, as well as analog recording traces as representative examples of them, are shown. $b$, Time course of the slope of the field EPSP after induction of early-LTP in S1 (filled circles). Open circles represent a control stimulated synaptic input, S2 ( $n=8)$. c, Transformation of early- into late-LTP by rolipram. Application of rolipram 30 min before stimulation of S1 (filled circles) with a tetanization protocol that normally would induce early-LTP (washout of the drug, 30 min after tetanization; open circles, control input; $n=7)$. $d$, The same experiment as in c with the exception that rolipram was applied 15 min after LTP induction for $1 \mathrm{hr}(n=7)$. e, The influence of the NMDA receptor blocker AP-5 on RLTP. After recording a baseline for $50 \mathrm{~min}, \mathrm{AP}-5$ was applied for 10 min before being coapplied with rolipram for another hour. Tetanization with a protocol that normally would induce early-LTP in S1 (filled circles) and control recording of S2 (open circles) ( $n=8)$. $f$, The same as in e but instead of AP-5, the reversible protein synthesis inhibitor anisomycin was applied 10 min before coapplication with rolipram for an additional hour $(n=7)$. Analog traces always represent typical field EPSPs $30 \mathrm{~min}$ before (dotted line), $30 \mathrm{~min}$ (dashed line) and $6 \mathrm{hr}$ (solid line) after tetanization of input $\mathbf{~ 1 , ~ o r ~ i n ~ c a s e s ~ i n ~ w h i c h ~} \mathbf{S 2}$ was also tetanized before or after the tetanization of that input. Arrows indicate the time point of tetanization of the corresponding synaptic input.

ferent phase of LTP allows us to speculate that PDEs could act as PRPs (Frey and Morris, 1998b; Sajikumar and Frey, 2004) whose synthesis is induced by the induction of long-lasting plastic events. A PDE would represent an ideal general PRP, because its direct effect on specifically regulating PKA activity could drive a synapse either to increase or decrease its efficacy, thus expressing LTP or LTD, respectively (Sajikumar and Frey, 2004). The action of rolipram was downstream of the $\mathrm{D}_{1} / \mathrm{D}_{5}$ receptor. Our previous hypothesis suggested that a synergistic action of glutamatergic and dopaminergic processes specifically regulates the synthesis of candidate PRPs such as the PDE4B3 (Sajikumar and Frey, 2004). This hypothesis is now strongly supported by our experiments 
a
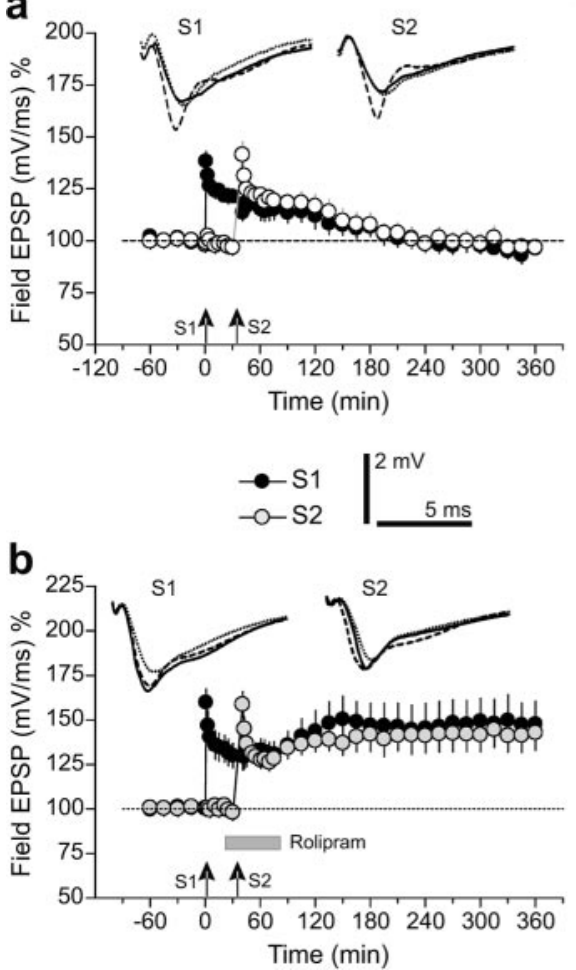

c
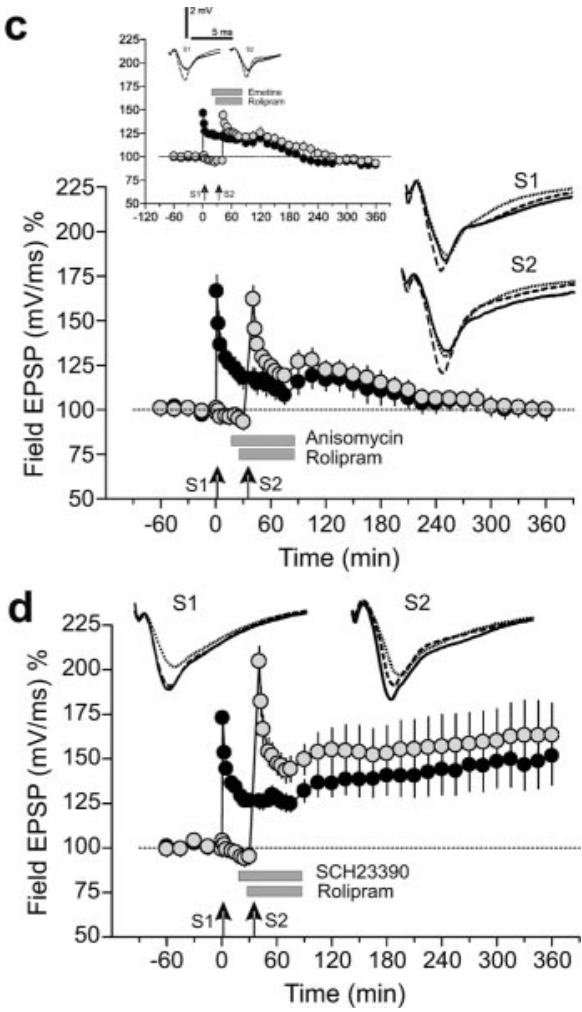

Figure 2. PDE inhibition by rolipram and synaptic tagging. $a$, Time course of the slope of field EPSPs after subsequent induction of early-LTP in S1 (filled circles) and S2 (open circles) with a time interval between tetanization of S1 and S2 of $40 \mathrm{~min}(n=7) . b$, Paradoxical transformation of early- into late-LTP in S1 (filled circles) by subsequent induction of RLTP in S2 40 min later (gray circles). Same stimulation protocol as in $a$ with the exception that, 15 min after tetanization of 51 , rolipram was added to the bath medium for $1 \mathrm{hr}$ before washout $(n=7)$. c, RLTP and synaptic tagging depend on protein synthesis. The same procedure as in $b$ with the exception of the additional application of anisomycin 5 min after tetanization of $S 1(n=10)$. The inset in crepresents the effect of a structurally different protein synthesis inhibitor, emetine, on RLTP, suggesting a specific action on protein synthesis by the drugs used. $d$, The action of rolipram is downstream of the $D_{1} / D_{5}$ receptors. When $S C H 23390$ was applied instead of anisomycin (as in c), neither the paradoxical transformation of early- into-LTP in S1 (filled circles) by subsequent RLTP induction in S2 (gray circles) nor RLTP in S2 were blocked $(n=7)$. Analog traces and arrows as in Figure 1.

presented here. Weak tetanization of a synaptic input S1, which would normally result only in early-LTP, was transformed into late-LTP if a subsequent RLTP was induced in input S2 (Fig. 2b). The explanation of that transformation could be as follows: earlyLTP was induced in synaptic input S1 sufficiently to activate a synaptic tag in this input. However, the tag as such is unable to convert early-LTP into late-LTP (Frey and Morris, 1997). When a subsequent weak tetanization was delivered to a synaptic input S2 in the presence of rolipram, however, both inputs now expressed late-LTP. Each of the tetanizations of S1 and S2 activated their synapse-specific tags, but only the weak tetanization of S2 under the influence of rolipram (i.e., PDE inhibition) resulted in the activation of synapse-nonspecific synthesis of PRPs that now could be captured by the synaptic tags in S1 and S2, thus being able to express late-LTP in the two inputs. Application of rolipram after the induction of early-LTP and without subsequent tetanization of a second synaptic input was unable to cause the same effect (Fig. 1d). Early-LTP induction must be coapplied with PDE repression to result in RLTP. Thus, induction of earlyLTP not only leads to the setting of a "tag" but is also involved in initiating synergistic events, together with PDE inhibition, that finally result in the synthesis of PRPs required for the expression of late-LTP. However, we cannot exclude that enzymes other than PDEs are also involved in regulating the synthesis of PRPs. Tagging of proteins in S1 whose synthesis was initiated by the
RLTP-dependent processes in input S2, 40 min after weak tetanization of $S 1$, supports our assumption that PDE may represent one PRP.

\section{References}

Ahmed T, Frey JU (2003) Expression of the specific type IV phosphodiesterase gene PDE4B3 during different phases of long-term potentiation in single hippocampal slices of rats in vitro. Neuroscience 117:627-638.

Ahmed T, Frey S, Frey JU (2004) Regulation of the phosphodiesterase PDE4B3-isotype during long-term potentiation in the area dentata in vivo. Neuroscience 124:857-867.

Atienza JM, Susanto D, Huang C, McCarty AS, Colicelli J (1999) Identification of inhibitor specificity determinants in a mammalian phosphodiesterase. J Biol Chem 274:4839-4847.

Barad M, Bourtchouladze R, Winder DG, Golan H, Kandel E (1998) Rolipram, a type IVspecific phosphodiesterase inhibitor, facilitates the establishment of long-lasting longterm potentiation and improves memory. Proc Natl Acad Sci USA 95:15020-15025.

Bear MF, Malenka RC (1994) Synaptic plasticity: LTP and LTD. Curr Opin Neurobiol 4:389-399.

Beavo JA (1988) Multiple isozymes of cyclic nucleotide phosphodiesterase. Adv Second Messenger Phosphoprotein Res 22:1-38.

Brandon EP, Zhuo M, Huang YY, Qi M, Gerhold KA, Burton KA, Kandel ER, McKnight GS, Idzerda RL (1995) Hippocampal long-term depression and depotentiation are defective in mice carrying a targeted disruption of the gene encoding the RI $\beta$ subunit of cAMP-dependent protein kinase. Proc Natl Acad Sci USA 92:8851-8855.

DeLapp NW, Eckols K (1992) Forskolin stimulation of cyclic AMP accumulation in rat brain cortex slices is markedly enhanced by endogenous adenosine. J Neurochem 58:237-242.

Donaldson J, Brown AM, Hill SJ (1988) Influence of rolipram on the cyclic $3^{\prime}, 5^{\prime}$-adenosine monophosphate response to histamine and adenosine in slices of guinea-pig cerebral cortex. Biochem Pharmacol 37:715-723.

Egawa T, Mishima K, Matsumoto Y, Iwasaki K, Iwasaki K, Fujiwara M (1997) Rolipram and its optical isomers, phosphodiesterase 4 inhibitors, attenuated the scopolamine-induced impairments of learning and memory in rats. Jpn J Pharmacol 75:275-281.

Frey S, Schweigert C, Krug M, Lossner B (1991) Long-term potentiation induced changes in protein synthesis of hippocampal subfields of freely moving rats: time-course. Biomed Biochim Acta 50:1231-1240.

Frey U, Morris RG (1997) Synaptic tagging and long-term potentiation. Nature 385:533-536.

Frey U, Morris RG (1998a) Weak before strong: dissociating synaptic tagging and plasticity-factor accounts of late-LTP. Neuropharmacology 37:545-552.

Frey U, Morris RG (1998b) Synaptic tagging: implications for late maintenance of hippocampal long-term potentiation. Trends Neurosci 21:181-188.

Frey U, Krug M, Reymann KG, Matthies H (1988) Anisomycin, an inhibitor of protein synthesis, blocks late phases of LTP phenomena in the hippocampal CA1 region in vitro. Brain Res 452:57-65.

Frey U, Hartmann S, Matthies H (1989) Domperidone, an inhibitor of the D2-receptor, blocks a late phase of an electrically induced long-term potentiation in the CA1-region in rats. Biomed Biochim Acta 48:473-476.

Frey U, Schroeder H, Matthies H (1990) Dopaminergic antagonists prevent long-term maintenance of posttetanic LTP in the CA1 region of rat hippocampal slices. Brain Res 522:69-75. 
Frey U, Huang YY, Kandel ER (1993) Effects of cAMP simulate a late stage of LTP in hippocampal CA1 neurons. Science 260:1661-1664.

Imanishi T, Sawa A, Ichimaru Y, Miyashiro M, Kato S, Yamamoto T, Ueki S (1997) Ameliorating effects of rolipram on experimentally induced impairments of learning and memory in rodents. Eur J Pharmacol 321:273-278.

Kameyama K, Lee HK, Bear MF, Huganir RL (1998) Involvement of a postsynaptic protein kinase A substrate in the expression of homosynaptic long-term depression. Neuron 21:1163-1175.

Krug M, Lossner B, Ott T (1984) Anisomycin blocks the late phase of longterm potentiation in the dentate gyrus of freely moving rats. Brain Res Bull 13:39-42.

Linden DJ (1996) A protein synthesis-dependent late phase of cerebellar long-term depression. Neuron 17:483-490.

Loughney K, Snyder PB, Uher L, Rosman GJ, Ferguson K, Florio VA (1999) Isolation and characterization of PDE10A, a novel human $3^{\prime}, 5^{\prime}$-cyclic nucleotide phosphodiesterase. Gene 234:109-117.

Matthies H, Reymann KG (1993) Protein kinase A inhibitors prevent the maintenance of hippocampal long-term potentiation. NeuroReport 4:712-714.

Nguyen PV, Kandel ER (1996) A macromolecular synthesis-dependent late phase of long-term potentiation requiring cAMP in the medial perforant pathway of rat hippocampal slices. J Neurosci 16:3189-3198.
Nicholson CD (1990) Pharmacology of nootropics and metabolically active compounds in relation to their use in dementia. Psychopharmacology (Berl) 101:147-159.

Otani S, Marshall CJ, Tate WP, Goddard GV, Abraham WC (1989) Maintenance of long-term potentiation in rat dentate gyrus requires protein synthesis but not messenger RNA synthesis immediately posttetanization. Neuroscience 28:519-526.

Rybalkin SD, Beavo JA (1996) Multiplicity within cyclic nucleotide phosphodiesterases. Biochem Soc Trans 24:1005-1009.

Sajikumar S, Frey JU (2003) Anisomycin inhibits the late maintenance of long-term depression in rat hippocampal slices in vitro. Neurosci Lett 338:147-150.

Sajikumar S, Frey JU (2004) Late-associativity, synaptic tagging and the role of dopamine during LTP and LTD. Neurobiol Learn and Mem 82:12-25.

Schneider HH (1984) Brain cAMP response to phosphodiesterase inhibitors in rats killed by microwave irradiation or decapitation. Biochem Pharmacol 33:1690-1693.

Stone EA, John SM (1990) In vivo measurement of extracellular cyclic AMP in the brain: use in studies of $\beta$-adrenoceptor function in nonanesthetized rats. J Neurochem 55:1942-1949.

Zhang HT, O'Donnell JM (2000) Effects of rolipram on scopolamineinduced impairment of working and reference memory in the radial-arm maze tests in rats. Psychopharmacology (Berl) 150:311-316. 